\title{
Brief Discussion on the Origin and Emotion of Ancient Chinese Poetry
}

\author{
Yongsheng Tian \\ North Minzu University, Yinchuan, China \\ Email: 1367292662@qq.com
}

How to cite this paper: Tian, Y.S. (2019)

Brief Discussion on the Origin and Emotion of Ancient Chinese Poetry. Open Access Library Journal, 6: e5712.

https://doi.org/10.4236/oalib.1105712

Received: August 8, 2019

Accepted: September 3, 2019

Published: September 6, 2019

Copyright () 2019 by author(s) and Open Access Library Inc.

This work is licensed under the Creative Commons Attribution International License (CC BY 4.0).

http://creativecommons.org/licenses/by/4.0/

\section{(c) (i) Open Access}

\begin{abstract}
Poetry is the earliest literary style in ancient China. It was originally presented as the "trinity of poetry, music and dance" and two words and three words as a form of beat. Ancient poetry originated from the labor production of the ancient society. With the awakening of human subject consciousness and the prosperity of ritual music culture, poetry was vigorously developed in the ritual etiquette and widely used in social life. The concept of "poems endowed with feelings" in ancient poetry theory profoundly summarizes and reveals that emotion is the internal cause of poet's creation of poetry, and plays the most important feature of judging poetry. The emotional source of poetry's creation of poetry often comes from the change of time and space, and the consciousness of time and space becomes an important perspective to explore poetry creation and thought and emotion.
\end{abstract}

\section{Subject Areas}

Literature

\section{Keywords}

Poetry, Origin, Labor, Poems Endowed with Feelings, Time and Space

Confucius talked about poetry and said that "Poetry can express emotions, observe the society, make friends, advise the king, honor the parents around you, contribute to the kings in the distance, and know the names of many birds, animals and plants" [1]. Confucius made the highest praise for the social role of poetry, because Chinese poetry is like a sea of smoke, stretching from thousands of years, and China is also called "the Kingdom of Poetry." Poetry is the earliest literary style in China and its origin and aesthetics have always been the subject of people's inquiry. 


\section{Ancient Poetry Originated from Labor}

In the history of Chinese literature, people often see the expression of "the trinity of poetry, music and dance". Why should poetry be combined with music and dance? This answer must fall on the issue of the origin of poetry. China mentioned that poetry is generally named after "poems and songs", indicating that "song" is also a poem. Ancient songs existed before the words that were produced. After the words were produced, people recorded these ancient songs. Therefore, the ancient songs have always appeared in the ancient poetry and poetry history compiled by later generations. What is the origin of poetry? At present, there are two important points in the academic world: one is "labor theory" and the other is "sacrificing theory." "Labor theory" believes that "the art of the first people occurred in the rhythm of labor so the songs and dances in ancient times were often twins" [2]; "the sacrificing theory" through the exploration of the original meaning of the "poetry", the theory of human culture. The perspective of the "Temple" is the person that presides over the rituals. He believes that "Poetry is a ritual with the nature of ritual and political integration. It is a prayer for ritual activities, with religious sacredness" [3]. These two viewpoints have their own rationale and research methods and are highly persuasive.

A long time ago, in ancient society, there was no difference between the wizards and the officials who recorded the history. As the status of ghosts and gods fell during the Shang and Zhou Dynasties, personnel attention was taken and the status of officials that recorded history gradually became independent and fixed. It is the wizards that have appeared earlier than the official historians and have been tasked with sacrificing and remembering history. In the ancient society, a long time ago, there should be no wizards. At that time, the society was the closest to the natural state. After walking upright on the ground, people gradually relied on tools for labor production and social division of labor. In the labor life of cultivation, hunting, eating, etc., people cannot do without language and people are the most emotional animals. It is instinct to communicate and express emotions by language. Lu Xun said, "Our ancestors, at that time, carrying wood together, everyone is very tired, but I don't know how to express it. One of them sings 'Hang $\mathrm{Yu}, \mathrm{Hang} \mathrm{Yu}^{\mathrm{\prime}}$ ', he belongs to creation. If some marks are left, It became literature" [4]. Language, rhythm and emotions have been recorded and become poems we can see. This is the standard for judging poetry in ancient and modern times. It also shows that labor is the earliest source of poetry. $\mathrm{Wu} \mathrm{Yue}$ Chun Qiu records a poem "Broken Bamboo, Continued Bamboo, Flying Earth, and Chasing Meat" hunting in ancient times. It should be the earliest poem in China. The forms of early poetry are two-character and three-word and the sense of rhythm is very short and strong. This also shows the poetry created in order to adapt to labor production. Later, during the Xia Dynasty and the Shang Dynasty in the feudal period, human beings had a heart of exploration and awe. Human beings began to imagine the existence of the gods, dominating the earth, 
and began the sacrificing activities of "communicating with God." Sacrifices need to express human desires and emotions, so language is needed. If the gods that sacrificed the sacrifices and the people that attended the sacrifices can clearly hear this expression and rhythmically come out, this becomes a poem. Later, the objects of sacrifice were gradually expanded upon the three categories of gods, earth immortals and human ghosts. The poems as sacrifices were more and more abundant. Therefore, we saw a lot of sacrificing poems in The Book of Songs.

Let's talk about why the early poems were merged with music and dance, still use Lu Xun's story about the ancestors carrying wood. It is poetry to express hard working emotions in rhythmic language. In order to better to coordinate movements, they need to use the same direction of posture and amplitude. It can be said that this picture has the earliest dance form. Of course, the dance at this time is purely a utilitarian implementation of some kind of productive labor, and has not yet been transformed into an artistic expression but it restricts the rhythm of slogan. In the labor production of ancient humans seeking survival and development, such as hunting, farming, war and other activities, the dance gradually matured and gradually became an art form with aesthetic effects. Therefore, poetry and dance were first combined. As for music, the original meanings of "sound" and "Yue" are different. Book of Rites says: "All sounds are produced because humans have the heart that can generate thoughts and feelings. Changes in human thoughts and feelings, It is the result of the influence of external things. Under the influence of external things, people's thoughts and feelings have changed and they will be expressed by "sound." Sound is not a kind, and there are similarities and differences. Then, intricate changes are made. The sounds of such intricate changes are expressed in a certain pattern, which is called sound and the sounds are played in order, and with the martial arts and the dance, it becomes a music" [5]. That is to say, the orderly change of the sound are called sound and the performance of the dance with the props is called music. Similarly, $L_{V}$ Shi Chun Qiu records "the music and dance of Ge Tianshi in the past, three people holding the oxtail, steppe on the pace to sing eight songs" can know that music cannot be separated from props and dance. In addition, in terms of literal meaning, the "Yue" in the Yin Shang oracle bones is often related to sacrifices. The original meaning of the word "Yue" in the creation of the word should be an integral part of the ritual to convey the reverence for the object of sacrifice. Therefore, at the beginning, poetry and dance, "Sound" combined, and later gradually combined with "music", evolved into the characteristics of the poetry and dance of early poetry.

\section{Emotion Is the Internal Cause of Poetry Creation}

Poetry in labor life produces poetry earlier than in sacrificing rituals. In the Zhou Dynasty, the ritual and music system was booming. Poetry was often produced and used in a series of ceremonial activities such as sacrifices, diplomatic 
relations, banquets, weddings, etc. so China has a reputation as a state of ritual and music since ancient times. However, our in-depth analysis will find that in poetry, etiquette is only the expression of the external form of poetry, and emotion is the internal motivation of poetry. It is with emotion that people have the desire to explore and the heart of awe, and there are ceremonial activities such as sacrifices. The Book of Songs says: "From the heart of people's feelings, and at the same time, it is the result of etiquette." It means that there is emotion and then etiquette, emotion is internal and etiquette is the external manifestation.

In the tradition of poetry theory, except "poems endowed with feelings", ancient Chinese literary theorists also have the views of "poems expressing wills" and "poem reason event". In fact, whether it is "poems expressing wills" or "poem reason event", in the final analysis, it is "poems endowed with feelings." Regarding the viewpoint of "poems expressing wills", Xu Shen's interpretation of "zhi" in Shuo Wen Jie Zi is "yi". Duan Yucai commented on "Zhi, Record". Explain that the original meaning of "Zhi" is in the mind the feeling is furthered to write the inner feelings, so Historical Records is called "poems expressing Yi". Shang Shu also says that poetry is used to express people's ideological desires. Similarly, Preface to MAO's Poems has: "there is emotion in the heart is the will, with language expression is poetry" [6]. This passage makes it clearer that poetry is an expression of people's emotional will.

Then we talk about the "poem reason event". This view was first proposed by the Western Han Dynasty scholar He Xiu. He said in the book Chun Qiu Gong Yang Zhuan Jie Gu that "men and women have resentful emotions and gather together to sing." Hungry people sing about food and laborers sing about farming." Later, in the Eastern Han Dynasty, Ban Gu talked about Yuefu poems in Han Shu: "The Yuefu poems are all because of the sorrow or sorrow of the creators in real life, which is a sigh from a specific event." These are the origins and theoretical basis of the "poetry" but when we dig deeper, we find two people talking about "things facing singing" and "lamenting specific things". They all said it was because of "feelings of resentment" and "being moved by sadness or joy."This is how poetry is created so the change of emotion is still the motivation of creation. From the perspective of specific works, including the "Sheng Ming" in The Book of Songs, "Gong Liu", "Mian", "Huang Yi", "Da Ming" and other poems known as "Zhou dynasty national epic". Although it is a review and record of the ancestor's establishment of Zhou Dynasty's deeds, it is also a kind of deed and praise and the pride is deeply contained in it. Therefore, the internal cause of "poem reason event" is also the change of emotion.

Belinsky, a famous Russian literary theorist, said: "Emotion is one of the most important motivations of poetic nature without feelings, there is no poet and no poetry" [7]. He affirmed that emotion is the fundamental feature of poetry art. In the history of ancient Chinese poetry criticism, the poetic concept of "poems endowed with feelings" has always occupied a dominant position since it was proposed by literary theorists, and has been continuously developed and im- 
proved. In addition, "poems endowed with feelings" is also the embodiment of the awakening of human subject consciousness.

\section{Time and Space Consciousness Is the Source of Poet's Emotion}

Marxist philosophy holds that "time and space are the forms of material movement and the movement away all things must be carried out in time and space" [8]. Time and space are two important dimensions for people to think about the existence of things. The two complement each other. From the beginning of the pre-Qin period in China, people think about time and space. For example, Taoist Lao $\mathrm{Zi}$ and Zhuang $\mathrm{Zi}$ once had profound insights and influences on time and space issues. It can be said that since people had the awareness and perception of time and space, then began to consciously "combine people's lives with eternal time, space without edges, and realize that human life is short and small, and then use eternal time and infinite space to reflect on life" [9]. People have realized the philosophy of it, and because of the changes in time and space, they have produced many sentiments. Expressing these sentiments using words, time and space and poetry have a deep fate. Time and space changes are most likely to cause people's emotional fluctuations. Poetry is often mixed with poets' sighs about the changes of time and space.

In terms of time consciousness, Lu Ji wrote in his book Wen Fu: "The changes in the four seasons make people lament that time is short, and the rise and fall of all things make people think" [10]. In the face of time, poets always feel that there is a great power controlling the rise and fall of all things and life. The phenological poem, poems of one's heart, poems on history are all the poets' experience of caring for the seasons, life and history. Therefore, we can often see poetry themes such as grieve over the passing of spring and feel sad about the advent of autumn or things are still there, but men are no more the same ones, or memory of the past, sad now. For example, The Book of Songs "Think that I just embarked on the journey, willows drooping branches depend on, now come home after the war, rain and snow all over the world" reveals the poet's feelings about "things are still there, but men are no more the same ones". Chu Ci "Remembering that the grass and trees are falling and withering in the autumn wind, my own worries about getting old arose sadly" expresses the emotion of "time is rushing, life is easy to be old". The famous Chinese poets Qu Yuan, Cao Cao, Ruan Ji, Tao Yuanming, Li Bai, Du Fu and so on have created a lot of poems that express time consciousness. In terms of space consciousness, the ancients had a profound concept of "Attached to the Land and Unwilling to Move." Therefore, faced with the change of space, poets often have feelings of parting sorrow and loneliness in the distance. Of course, different spatial changes will produce different emotions. For example, both the poets that went to frontier and the poets that were demoted had homesickness but the former had many desires to make meritorious deeds and the latter had many feelings of 
frustration and depression. Gathering and parting are the poet's most direct feelings about space consciousness, whether it is their own departure or the departure of friends and relatives, it is so sad. Nineteen Ancient Poems in the poem "The longer they are separated from each other, the wider their clothes and the thinner they are" being a very appropriate expression of the sincere feelings.

It can be said that from The Book of Songs and $C h u C i$ in the pre-Qin period of China, to the Nineteen Ancient Poems in the Han Dynasty, in these early poems, time and space consciousness has been permeated through the emotions of poetry. In addition, the sense of time and space is often blended in poetry and the emotions produced by the changes in time and space are often expressed through the imagery of poetry. In The Book of Changes, it is said that "the image is created to fulfill the meaning". In Wen Xin Diao Long by Liu Xie, it is said that" Emotions are contained in imagery". They all clearly show the truth that emotions are expressed through imagery. The images of autumn wind, bright moon, and returning geese in poetry are all products of the poet's time and space consciousness.

The academic circles have many viewpoints on the origin of ancient Chinese poetry. This article studies the phenomena and linguistic features in the trinity of poetry, music and dance in ancient songs and then combines the analysis of early social characteristics. In the end, it is concluded that ancient Chinese poetry should originate from labor production. After the awakening of human subject consciousness, poetry began to be closely related to ceremonial activities such as sacrifice. By further analyzing the inner form of poetry, it is concluded that emotion is the internal cause of poet's creation of poetry. The change of time and space is the source of poet's emotion. Time and space consciousness play a key role in understanding poet thoughts and interpreting poetry emotions. In addition, the analysis method of time and space dimensions can also be used in the appreciation and teaching of classical poetry.

\section{Conflicts of Interest}

The author declares no conflicts of interest regarding the publication of this paper.

\section{References}

[1] Yang, B.J. (1980) Analects Annotation. Zhonghua Book Company, Beijing.

[2] Lin, G. (1995) A Brief History of Chinese Literature. Peking University Press, Beijing.

[3] Ye, S.X. (2004) Cultural Interpretation of the Book of Songs. Shaanxi People's Publishing House, Xi'an.

[4] Lu, X. (2013) Qie Jieting Essay. Yilin Publishing House, Jiangsu.

[5] Kong, Y.D. (2008) The Correct Meaning of the Book of Rites. Shanghai Ancient Books Publishing House, Shanghai. 
[6] Li, X.Q. (1999) The Correct Meaning of MAO’s Poems. Peking University Press, Beijing.

[7] Editorial Committee of Foreign Literature Research Materials Series, Institute of Foreign Literature, Chinese Academy of Social Sciences (1979) Foreign Theorist Writers on Image Thinking. China Social Sciences Press, Beijing.

[8] Central Compilation Bureau (1971) The Complete Works of Marx and Engels. People's Publishing House, Beijing.

[9] Zhang, H.Y. (2002) Time and Space Poetics. Ningxia People's Publishing House, Ningxia.

[10] Zhang, S.K. (2002) Wen Fu Annotation Collection. People's Publishing House, Beijing. 